\title{
Alice In Wonderland Syndrome: Case Report
}

\author{
Buyukgol $\mathrm{H}^{1^{*}}$, Gunes $\mathrm{M}^{2}$ and Eren $\mathrm{FA}^{2}$ \\ ${ }^{1}$ KTO Karatay University Medicana Faculty of Medicine, Department of Neurology, Konya, Turkey \\ ${ }^{2}$ Aksaray Training and Research Hospital, Department of Neurology, Aksaray, Turkey
}

*Corresponding author: Buyukgol H, KTO Karatay University Medicana Faculty of Medicine, Department of Neurology, Konya, Turkey, Tel: 00905336142789, E-mail: h_buyukgol@hotmail.com

Citation: Buyukgol H, Gunes M, Eren FA (2018) Alice In Wonderland Syndrome: Case Report. J Neurosci Neuropsyc 2: 101. doi: 10.18875/2577-7890.2.101

Article history: Received: 16 November 2017, Accepted: 09 January 2018, Published: 11 January 2018

\begin{abstract}
Alice In Wonderland Syndrome (AIWS) is a syndrome characterized by visual distortions, like seeing objects or body images as being larger than normal (macropsia), smaller than normal. A 30-year-old male patient applied to our clinic with a complaint of long-term headache episodes. Presented with a pulsating headache on the left side of his head which had lasted for approximately 24 hours and usually occurred once a week in the form of attacks. his fingers appeared to be smaller than they actually were, and that he noticed deformations in the objects around him before the pain began. He reported that all these visual distortions would continue for almost half an hour. For initial treatment in our case, we administered $500 \mathrm{mg}$ /day of valporic acid, increasing it to $1000 \mathrm{mg} /$ day during follow-ups. No attacks were observed in the 3-month follow-up. AIWS has been reported in migraine, complex partial seizure, infectious mononucleosis, and non-specific hyperprexia cases. We present an AIWS case coexistent with aura-involved migraine.
\end{abstract}

Keywords: Alice in wonderland; Migraine; Macropsia

\section{Introduction}

Alice In Wonderland Syndrome (AIWS) is a syndrome characterized by visual distortions (metamorphopsia), like seeing objects or body images as being larger than normal (macropsia), smaller than normal (micropsia), longer or shorter than normal, or thinner or thicker than normal, and by perception disorders, like seeing things as being farther than normal (teleopsia) or closer than normal (pelopsia), and by visual hallucinations [1]. In 1952, Lippman diagnosed these distortions in body images in seven migraine patients [2]. Todd designated this syndrome as AIWS in 1955 [3]. It has been reported in migraine, complex partial seizure, infectious mononucleosis, and non-specific hyperprexia cases [4]. We present an AIWS case coexistent with aura-involved migraine.

\section{Case}

A 30-year-old male patient applied to our clinic with a complaint of long-term headache episodes. The patient presented with a pulsating headache on the left side of his head which had lasted for approximately 24 hours and usually occurred once a week in the form of attacks. During his headaches, nausea was accompanied with photophobia and phonophobia. The patient stated that the objects around him appeared to be larger than they actually were, that his fingers appeared to be smaller than they actually were, and that he noticed deformations in the objects around him. Headache started after approximately 30 minutes after these symptoms. These auras are not seen in every attack. He had seen this visual phenomenon for about 1 year. He reported that all these visual distortions would continue for almost half an hour. Besides his mother's and sister's history of migraines, there were no significant characteristics in the patient's background. His psychiatric examination was normal, Results from the neurological and systemic examination of the patient were normal, and his blood test results were at normal limits. No pathologies were detected in the brain magnetic resonance imaging (MRI) and the electroencephalography (EEG) that were taken. Two of them were normally. The patient was administered $500 \mathrm{mg}$ /day of valporic acid. Complaints improved, but repeated. During follow-ups, valporic acid was increased to $1000 \mathrm{mg} / \mathrm{day}$, and the complaints of the patient were completely eliminated.

\section{Discussion}

Migraine with aura occurs either as an isolated episode or together with attacks of migraine without aura in $10 \%$ of all migraines [5]. 
Migraine with aura is a primary headache, where reversible focal neurological symptoms develop over 5-10 minutes, last for less than 60 minutes and manifest with recurrent attacks. The type of migraine with aura varies depending on migraine sub-groups, but the auras can involve visual symptoms (lights, spots, lines, blurred vision, etc.), sensory symptoms (numbness, pricking, etc.), motor weaknesses and speech disorders [6]. This syndrome characterized by visual distortions (metamorphopsia), such as seeing objects or body images as being larger than normal (macropsia), smaller than normal (micropsia), longer or shorter than normal, or thinner or thicker than normal, by perception distortions, such as seeing things as being farther away than they really are (teleopsia) or closer than they really are (pelopsia), and by visual hallucinations [1]. The headache experienced by our subject was migraine with aura, which involved two major symptoms, namely, pain that lasted for almost 24 hours and a period of aura that lasted for half an hour. These symptoms, specifically, the macropsia, microspia and metamorphopsia described by the patient, are consistent with AIWS. In epilepsy, schizophrenia, intoxication-induced migraine, EBV infections, and other central nervous system infections, AIWS is associated with the use of hallucinogenic drugs and hyperprexy [7]. In our case, there was no history of psychiatric disorder, hallucinogenic drug use or central nervous system infection, the patient had no pathologies in his EEG, and the AIWS was not associated with migraine. AIWS can be seen in temporo-occipital or temporo-partial-occipital lesions [4]. Our case had no pathologies in the brain MRI. Data on the treatment of AIWS is limited. In one study conducted on the treatment of migraine, verapamil was reported to be $55 \%$ effective, while valporic acid was determined to be $18 \%$ effective [8]. For initial treatment in our case, we administered $500 \mathrm{mg} /$ day of valporic acid, increasing it to $1000 \mathrm{mg} /$ day during follow-ups. Because in a study, valproic acid has been shown to be beneficial in the case of migraine-induced AIWS [4]. No attacks were observed in the 3-month follow-up. Although valporic acid has been shown to be less effective in the reported studies, it may be useful in these cases involving migraine with aura. This should be kept in mind during treatment.

\section{References}

1. Liu GT, Galetta SL, Volpe NJ (2010) Visual hallucinations and illusions. In: Neuro-ophthalmology Diagnosis and Management (2 ${ }^{\text {nd }}$ edn) Elsevier, London, 398-9.

2. Lippman CW (1952) Certain hallucinations peculiar to migraine. J Nerv Ment Dis 116: 346-51.

3. Todd J (1955) The syndrome of Alice in Wonderland. Can Med Assoc J 73: 701-4.

4. Ilik F, Ilik K (2013) Alice in Wonderland syndrome as aura of migraine. Neurocase 20: 474-5.

5. Srinivasa R, Kumar R (2010) Migraine variants and beyond. J Assoc Physicians India 58: 14-7.

6. Headache classification Subcommittee of the International Headache Society (2004) The International Classification of Headache Disorders. Cephalalgia 24: 9-160.

7. Kitchener N (2004) Alice in Wonderland syndrome. Int J Child Neuropsychiatry 1: 107-12.

8. Evans RW, Lipton RB (2001) Topics in migraine management: A survey of headache specialists highlights some controversies. Neurol Clin 19: 1-21. 